\title{
Ki-67 (30-9) scoring and differentiation of Luminal A- and Luminal B-like breast cancer subtypes
}

\author{
Giuseppe Viale ${ }^{1,2} \cdot$ Amy E. Hanlon Newell ${ }^{3}$ Espen Walker ${ }^{3} \cdot$ Greg Harlow $^{3}$ - Isaac Bai ${ }^{3}$. Leila Russo ${ }^{1}$. \\ Patrizia Dell'Orto $^{1} \cdot$ Patrick Maisonneuve $^{4}$
}

Received: 16 June 2019 / Accepted: 7 August 2019 / Published online: 17 August 2019

(c) The Author(s) 2019

\begin{abstract}
Introduction Ki-67 labeling index assessed by immunohistochemical assays has been shown useful in assessing the risk of recurrence for estrogen receptor (ER)-positive HER2-negative breast cancers (BC) and distinguishing Luminal A-like from Luminal B-like tumors. We aimed to assess the performance of the Ventana CONFIRM anti-Ki-67 (30-9) Rabbit Monoclonal Primary Antibody.

Methods We constructed a case-cohort design based on a random sample $(n=679)$ of all patients operated on for a first primary, non-metastatic, ER-positive, HER2-negative BC at the European Institute of Oncology (IEO) Milan, Italy during 1998-2002 and all additional patients $(n=303)$ operated during the same period, who developed an event (metastasis in distant organs or death due to $\mathrm{BC}$ as primary event) and were not included in the previous subset. Multivariable Cox proportional hazards regression with inverse subcohort sampling probability weighting was used to evaluate the risk of event according to Ki-67 (30-9) and derived intrinsic molecular subtype, using previously defined cutoff values, i.e., respectively $14 \%$ and $20 \%$. Results $\mathrm{Ki}-67$ was $<14 \%$ in 318 patients (32.4\%), comprised between 14 and $19 \%$ in 245 patients $(24.9 \%)$ and $\geq 20$ in 419 patients (42.7\%). At multivariable analysis, the risk of developing distant disease was 1.88 (95\% CI 1.20-2.93; $P=0.006$ ) for those with Ki-67 comprised between 14 and 19\%, and 3.06 (95\% CI 1.93-4.84; $P<0.0001$ ) for those with Ki-67 $\geq 20 \%$ compared to those with Ki-67 $<14 \%$. Patients with Luminal B-like BC had an approximate twofold risk of developing distant disease $(\mathrm{HR}=1.91 ; 95 \%$ CI 1.35-2.71; $P=0.0003)$ than patients with Luminal A-like BC defined using Ki-67 (30-9). Conclusions $\mathrm{Ki}-67$ evaluation using the 30-9 rabbit monoclonal primary antibody was able to stratify patients with ERpositive HER2-negative BC into prognostically distinct groups. Ki-67 assessment, with strict adherence to the international recommendations, should be included among the clinically useful biological parameters for the best treatment of patients with BC.
\end{abstract}

Keywords Ki-67 $\cdot$ Luminal A $\cdot$ Luminal B $\cdot$ Differentiation $\cdot$ Biomarker

Presented in part at the San Antonio Breast Cancer Symposium, December 4-8, 2018, San Antonio, TX.

Electronic supplementary material The online version of this article (https://doi.org/10.1007/s10549-019-05402-w) contains supplementary material, which is available to authorized users.

Greg Harlow

greg.harlow@roche.com

1 Department of Pathology, IEO European Institute of Oncology IRCCS, Milan, Italy

2 University of Milan, Milan, Italy

3 Ventana Medical Systems, Inc., Tucson, AZ, USA

4 Division of Epidemiology and Biostatistics, IEO European Institute of Oncology IRCCS, Milan, Italy

\section{Introduction}

$\mathrm{Ki}-67$ is a nuclear antigen expressed by all proliferating cells during late $\mathrm{G} 1$ through the $\mathrm{M}$ phases of the cell cycle, peaking in the G2-M and with a rapid decline after mitosis [1]. Ki-67 labeling index assessed by immunohistochemical assays is a powerful prognostic marker in breast cancer. It is especially useful in assessing the risk of recurrence for estrogen receptor (ER)-positive HER2-negative breast cancers, where it may be considered a surrogate of the molecular assays for distinguishing Luminal A-like from Luminal B-like tumors [2]. Despite methodological problems still exist in the determination of $\mathrm{Ki}-67$ in the routine clinical practice, both the Panellists of the St. Gallen Consensus [3] 
and the European Group on Tumor Markers (EGTM) [4] have endorsed use of Ki-67 in combination with established prognostic factors for determining prognosis, especially if values are low (e.g. $<10 \%$ of immunostained tumor cells) or high (e.g. $>25 \%$ cell staining). The higher cutoff value is based on a meta-analysis showing that a threshold of $>25 \%$ cell staining was associated with a greater risk of death compared with lower values [5].

The mouse monoclonal antibody MIB-1 was the first antibody to be raised against a formalin-resistant epitope of Ki-67, and it has been extensively used in both clinical research and routine practice [6].

We evaluated the performance of the CONFIRM antiKi-67 (30-9) Rabbit Monoclonal Primary Antibody in assessing the risk of distant relapses in a large series of patients with ER-positive HER2-negative breast cancer treated and followed up in a single Institution.

\section{Materials and methods}

\section{Patients selection}

The initial cohort (9415 patients) comprised all women operated on for a first primary, non-metastatic, ER-positive HER2 negative, breast cancer (BC) at the European Institute of Oncology (IEO) Milan, Italy, who did not receive neoadjuvant treatment [7]. We subsequently restricted the cohort to 3986 patients operated on between 1998 and 2002 and for whom long-term follow-up data were available. A case-cohort [8] was built by randomly selecting approximately $17 \%$ of the above cohort $(n=679)$. Additional patients $(n=303)$ who developed an event (metastasis in distant organs or death due to $\mathrm{BC}$ as primary events) were added to this cohort (Supplementary Fig. 1).

\section{Laboratory methods}

Ki-67 was evaluated using the VENTANA CONFIRM antiKi-67 (30-9) Rabbit Monoclonal Primary Antibody (Ventana Medical Systems, Inc., Tucson, AZ) using OptiView IHC DAB detection on the BenchMark ULTRA advanced staining platform. The stained slides were evaluated at the IEO by certified pathologists trained to score Ki-67 according to the recommendations of the International Ki-67 in Breast Cancer Working Group [9].

Samples were retrieved from the Pathology archives with Institutional Review Board approval and classified as 'Luminal A-like'; estrogen receptor (ER)-positive, HER2-negative tumors with "low" Ki-67 $(<14 \%)$ or with "intermediate" Ki-67 (14-19\%) and "high" progesterone receptor expression ( $\mathrm{PgR} \geq 20 \%)$, and 'Luminal B-like'; HER2 negative, tumors ER positive, HER2 negative, with "intermediate"
Ki-67 (14-19\%) and "low" PgR $(<20 \%)$ or with "high" Ki-67 ( $\geq 20 \%$ ) [7] (Supplementary Table 1).

\section{Statistical methods}

Associations between clinicopathological characteristics and Ki-67 expression were evaluated with the Mantel-Haenszel test for trend. The main outcome was distant disease-free survival (DDFS) and was calculated from the date of surgery to the date of any first event or the date of last contact with the patient. Distant disease was defined as the occurrence of metastasis in distant organs or death due to $\mathrm{BC}$ as primary events. The rate of events in the subcohort was calculated dividing the number of events recorded during follow-up by the total number of patient-years accumulated during the observation period and $95 \%$ confidence intervals calculated using the mid-P exact method. Cumulative incidence curves were drawn for patients in the subcohort using the Kaplan-Meier method and difference between patient subgroups was assessed using the log-rank test. Multivariable Cox proportional hazards regression with inverse subcohort sampling probability weighting was used to evaluate the risk of metastasis or death from $\mathrm{BC}$ across groups in the combined case-cohort $[10,11]$. In the multivariable analysis, Ki-67 was considered either as a continuous variable, expressing the hazard ratio (HR) for each $10 \%$ increase of $\mathrm{Ki}-67$ labeling index or was categorized using the same cutoff values used for the definition of surrogate $\mathrm{BC}$ molecular subtypes, i.e., respectively $14 \%$ and 20\% [7]. Other variables considered in the multivariable analysis include menopausal status, pathological T (pT1, pT2, pT3/4), regional lymph node status (pN0, pN+), tumor grade $(\mathrm{G} 1, \mathrm{G} 2, \mathrm{G} 3)$, peritumoral vascular invasion (PVI) (absent, present), estrogen receptor (ER) and progesterone receptor (PgR) expression ( $<20 \%$ vs. $\geq 20 \%$ ) and adjuvant treatment (none, hormone therapy alone, or hormone therapy plus chemotherapy). Finally, restricted cubic spline Cox regression models were applied to assess dose-response relationships. Analyses were carried out with the SAS software (version 9.4, Cary NC). $P$ values were two sided. $P<0.05$ were considered statistically significant.

\section{Results}

The case-cohort comprised 982 patients (679 patients are part of the 1998-2002 subcohort (including 84 with event) and 303 are patients who developed event outside of the subcohort (Supplementary Fig. 1). Of the 387 events, 10 were death from breast cancer as a first event, and the remaining 377 were distant metastases, with a prevalence of bone metastases (155 events) followed by lung (46 events) and 
liver metastases (44 events). Ninety-five patients developed multiple metastases as first event.

Distribution of Ki-67 according to clinicopathological characteristics is displayed in Table 1. Overall, the median Ki-67 expression was $18 \%$, in 318 patients (32.4\%) it was $<14 \%$, in 245 patients (24.9\%) it was comprised between 14 and $19 \%$ and in 419 patients $(42.7 \%)$ it was $\geq 20 \%$. Distribution was significantly different across all subgroups evaluated, Ki-67 expression being significantly higher in premenopausal women $P=0.0002$ ), and being directly associated with $\mathrm{pT}, \mathrm{pN}$, tumor grade, presence of PVI, and inversely associated with the expression of ER and PgR receptors
$(P<0.0001$ for all the associations). Particularly elevated median Ki-67 expression (27\%) was found in patients with poorly differentiated tumors and in patients with tumors showing low (1-19\% immunoreactive tumor cells) or moderate (20-49\% immunoreactive tumor cells) ER expression, and with a median $\mathrm{Ki}-67$ value of $35 \%$ and $27 \%$, respectively. Lowest median Ki-67 was observed in patients with well-differentiated tumors (median 9\%).

In the subcohort, 84 patients developed distant disease or died from BC as first event during follow-up, corresponding to an event rate of 1.60 per 100 patient-year (Table 2). The event rate increased from 0.61 per 100 patient-year for

Table 1 Distribution of Ki-67 (30-9) according to selected clinicopathological characteristics

\begin{tabular}{|c|c|c|c|c|c|c|c|}
\hline & \multirow[t]{2}{*}{ Patients } & \multicolumn{6}{|l|}{ Ki-67 (30-9) } \\
\hline & & Median (25th-75th) & Mean Std. Dev & $\begin{array}{l}<14 \% \\
\mathrm{~N}(\%)\end{array}$ & $\begin{array}{l}14-19 \% \\
\mathrm{~N}(\%)\end{array}$ & $\begin{array}{l}\geq 20 \% \\
N(\%)\end{array}$ & $P$ value* \\
\hline All & 982 & $18(12-25)$ & $19.6 \pm 11.9$ & $318(100)$ & $245(100)$ & $419(100)$ & \\
\hline \multicolumn{8}{|l|}{ Menopausal status } \\
\hline Pre/peri & 434 & $19(13-26)$ & $21.2 \pm 12.6$ & $115(36.2)$ & $109(44.5)$ & $210(50.1)$ & \\
\hline Post & 548 & $16(11-24)$ & $18.4 \pm 11.1$ & $203(63.8)$ & $136(55.5)$ & 209 (49.9) & 0.0002 \\
\hline \multicolumn{8}{|l|}{ pT } \\
\hline pT1 & 590 & $15(10-22)$ & $16.9 \pm 10.2$ & $245(77.0)$ & $160(65.3)$ & $185(44.2)$ & \\
\hline pT2 & 343 & $22(16-29)$ & $24.3 \pm 13.4$ & $61(19.2)$ & $72(29.4)$ & $210(50.1)$ & \\
\hline $\mathrm{pT} 3 / 4$ & 49 & $19(14-25)$ & $19.7 \pm 8.5$ & $12(3.8)$ & $13(5.3)$ & $24(5.7)$ & $<0.0001$ \\
\hline \multicolumn{8}{|l|}{$\mathrm{pN}$} \\
\hline pNO & 459 & $16(10-22)$ & $17.7 \pm 12.5$ & $195(61.3)$ & $107(43.7)$ & $157(37.5)$ & \\
\hline 1-3 Positive nodes & 292 & $18(13-25)$ & $20.0 \pm 11.2$ & $81(25.5)$ & $86(35.1)$ & $125(29.8)$ & \\
\hline$\geq 4$ Positive nodes & 212 & $22(16-29)$ & $23.3 \pm 10.2$ & $35(11.0)$ & 48 (19.6) & $129(30.8)$ & $<0.0001$ \\
\hline $\mathrm{pNx}$ & 19 & $16(7-25)$ & $19.5 \pm 14.5$ & $7(2.2)$ & $4(1.6)$ & $8(1.9)$ & \\
\hline \multicolumn{8}{|l|}{ Grade } \\
\hline G1 & 181 & $9(5-14)$ & $10.5 \pm 6.6$ & $131(41.2)$ & $34(13.9)$ & $16(3.8)$ & \\
\hline G2 & 489 & $16(12-21)$ & $17.0 \pm 8.0$ & $169(53.1)$ & $170(69.4)$ & $150(35.8)$ & \\
\hline G3 & 286 & $27(22-34)$ & $30.1 \pm 13.0$ & $8(2.5)$ & $35(14.3)$ & $243(58.0)$ & $<0.0001$ \\
\hline Unknown & 26 & $17(10-24)$ & $17.3 \pm 7.8$ & $10(3.1)$ & $6(2.4)$ & $10(2.4)$ & \\
\hline \multicolumn{8}{|l|}{ PVI } \\
\hline Absent & 672 & $16(10-23)$ & $17.8 \pm 11.3$ & $263(82.7)$ & $169(69.0)$ & $240(57.3)$ & \\
\hline Present & 310 & $22(16-28)$ & $23.5 \pm 12.2$ & $55(17.3)$ & $76(31.0)$ & $179(42.7)$ & $<0.0001$ \\
\hline \multicolumn{8}{|l|}{ ER } \\
\hline $1-19 \%$ & 17 & $35(28-50)$ & $38.7 \pm 19.5$ & $0(0.0)$ & $4(1.6)$ & $13(3.1)$ & \\
\hline $20-49 \%$ & 61 & $27(17-30)$ & $25.2 \pm 13.0$ & $13(4.1)$ & $12(4.9)$ & $36(8.6)$ & \\
\hline$\geq 50 \%$ & 904 & $19(12-27)$ & $21.6 \pm 13.5$ & 305 (95.9) & $229(93.5)$ & $370(88.3)$ & $<0.0001$ \\
\hline \multicolumn{8}{|l|}{$\operatorname{PgR}$} \\
\hline $1-20 \%$ & 309 & $21(14-30)$ & $23.2 \pm 14.2$ & $86(27.0)$ & $75(30.6)$ & $148(35.3)$ & \\
\hline $20-49 \%$ & 180 & $22(14-29)$ & $22.9 \pm 13.3$ & $52(16.4)$ & $38(15.5)$ & $90(21.5)$ & \\
\hline$\geq 50 \%$ & 493 & $18(12-26)$ & $21.2 \pm 13.6$ & $180(56.6)$ & $132(53.9)$ & $181(43.2)$ & 0.001 \\
\hline \multicolumn{8}{|l|}{ Adjuvant treatment } \\
\hline None & 41 & $12(6-19)$ & $15.0 \pm 13.3$ & $25(7.9)$ & $6(2.4)$ & $10(2.4)$ & \\
\hline Hormone therapy & 470 & $14(10-21)$ & $15.8 \pm 9.4$ & $217(68.2)$ & $119(48.6)$ & $134(32.1)$ & \\
\hline Chemotherapy & 470 & $22(16-29)$ & $23.9 \pm 12.5$ & $76(23.9)$ & $120(49.0)$ & $274(65.4)$ & $<0.0001$ \\
\hline
\end{tabular}

*P-value based on the Mantel-Haenszel Chi square test for trend 
Table 2 Distribution of events and multivariable analysis

\begin{tabular}{|c|c|c|c|c|c|c|}
\hline & \multicolumn{3}{|c|}{ Sub-cohort $(n=679)$} & \multirow{2}{*}{$\begin{array}{l}\text { Additional } \\
\text { cases } \\
(n=303)\end{array}$} & \multicolumn{2}{|c|}{ Case-cohort $(n=982)$} \\
\hline & Patients & Events & $\begin{array}{l}\text { Event rate per } 100 \\
\text { patient-year }(95 \% \\
\text { CI) }\end{array}$ & & $\operatorname{HR}(95 \% \mathrm{CI})^{\mathrm{a}}$ & $P$-value \\
\hline \multicolumn{7}{|l|}{$\mathrm{Ki}-67(30-9)^{\mathrm{b}}$} \\
\hline$<14 \%$ & 278 & 14 & $0.61(0.35-1.00)$ & 40 & 1.00 & \\
\hline $14-19 \%$ & 171 & 20 & $1.47(0.92-2.23)$ & 74 & $1.88(1.20-2.93)$ & 0.006 \\
\hline$\geq 20 \%$ & 230 & 50 & $3.12(2.34-4.08)$ & 189 & $3.06(1.93-4.84)$ & $<0.0001$ \\
\hline \multicolumn{7}{|l|}{ Menopausal status } \\
\hline Pre/peri & 289 & 34 & $1.50(1.05-2.07)$ & 145 & 1.00 & \\
\hline Post & 390 & 50 & $1.68(1.26-2.20)$ & 158 & $1.43(0.82-2.49)$ & 0.20 \\
\hline \multicolumn{7}{|l|}{ pT } \\
\hline pT1 & 466 & 34 & $0.88(0.62-1.22)$ & 124 & 1.00 & \\
\hline pT2 & 191 & 44 & $3.51(2.58-4.67)$ & 152 & $1.75(1.24-2.45)$ & 0.001 \\
\hline $\mathrm{pT} 3 / 4$ & 22 & 6 & $4.41(1.79-9.18)$ & 27 & $3.26(1.66-6.39)$ & 0.0006 \\
\hline \multicolumn{7}{|l|}{$\mathrm{pN}$} \\
\hline pNO & 378 & 18 & $0.57(0.35-0.89)$ & 81 & 1.00 & \\
\hline $\mathrm{pN}+$ & 402 & 64 & $3.22(2.50-4.09)$ & 121 & $1.86(1.25-2.78)$ & 0.002 \\
\hline \multicolumn{7}{|l|}{ Grade } \\
\hline G1 & 166 & 6 & $0.42(0.17-0.87)$ & 15 & 1.00 & \\
\hline $\mathrm{G} 2$ & 343 & 36 & $1.36(0.96-1.86)$ & 146 & $1.90(1.06-3.39)$ & 0.03 \\
\hline G3 & 151 & 40 & $3.91(2.83-5.28)$ & 135 & $2.43(1.27-4.65)$ & 0.008 \\
\hline \multicolumn{7}{|l|}{ PVI } \\
\hline Absent & 510 & 45 & $1.10(0.81-1.46)$ & 162 & 1.00 & \\
\hline Present & 169 & 39 & $3.36(2.42-4.55)$ & 141 & $1.53(1.11-2.12)$ & 0.009 \\
\hline \multicolumn{7}{|l|}{ ER } \\
\hline$\geq 20 \%$ & 665 & 81 & $1.57(1.26-1.94)$ & 300 & 1.00 & \\
\hline$<20 \%$ & 14 & 3 & $3.06(0.78-8.33)$ & 3 & $1.05(0.43-2.61)$ & 0.91 \\
\hline \multicolumn{7}{|l|}{$\mathrm{PgR}$} \\
\hline$\geq 20 \%$ & 474 & 53 & $1.45(1.10-1.88)$ & 199 & 1.00 & \\
\hline$<20 \%$ & 205 & 31 & $1.95(1.35-2.73)$ & 104 & $1.01(0.72-1.41)$ & 0.98 \\
\hline \multicolumn{7}{|l|}{ Adjuvant treatment } \\
\hline None & 34 & 3 & $1.22(0.31-3.33)$ & 7 & $1.50(0.61-3.69)$ & 0.37 \\
\hline Hormone therapy & 382 & 20 & $0.64(0.39-0.94)$ & 88 & 1.00 & \\
\hline Chemotherapy & 262 & 61 & $3.18(2.45-4.06)$ & 208 & $1.73(1.11-2.69)$ & 0.02 \\
\hline
\end{tabular}

${ }^{a}$ Hazards ratio (HR and 95\% confidence intervals (CI) obtained from Cox proportional Hazards regression with inverse subcohort sampling probability weighting as defined in Miettinen (1976) using the SAS macro CCREGRESSION provided by Kulathinal et al. (2007)

${ }^{\mathrm{b}}$ Results of an alternative multivariable model with Ki-67 (30-9) set as a continuous variable shows $\mathrm{HR}=1.25(95 \% \mathrm{CI} 1.08-1.44 ; P=0.002)$ for a $10 \%$ increase Ki-67, adjusted for menopausal status, pT, $\mathrm{pN}$, grade, $\mathrm{PVI}, \mathrm{ER}, \mathrm{PgR}$ and adjuvant therapy patients with low Ki-67 $(<14 \%)$, to 1.47 per 100 patientyear for those with intermediate Ki-67 (14-19\%) and to 3.12 per 100 patient-year for those with Ki-67 $\geq 20 \%$. The 10 -year cumulative incidence of distant metastasis (or BC-related death as first event) according to categories of $\mathrm{Ki}-67$ is shown in Fig. 1. The event rate was about constant over time in the three groups. At 5 years and 10 years, respectively, $2.7 \%$ (95\% CI $1.3-5.5)$ and $6.4 \%$ (95\% CI 3.8-10.7) of patients with Ki-67<14\% developed an event against $6.8 \%$ (95\% CI 3.8-11.9) and $13.5 \%$ (95\% CI 8.9-20.3) of those with intermediate $\mathrm{Ki}-67$, and $15.2 \%$ (95\% CI 11.0-20.8) and $26.6 \%$ (95\% CI 20.7-33.8) of those with high Ki-67.

Dose-response in the subcohort was further evaluated in a plot based on a restricted cubic spline Cox regression model (Fig. 2): the rate of events increased linearly with the increasing expression of $\mathrm{Ki}-67$ for values comprised between 0 and $30 \%$. Above this threshold, the rate of events increased only slightly, and was based on a small fraction of the patients (only $79(12 \%)$ patients in the subcohort had Ki-67 $\geq 30 \%$ ). 

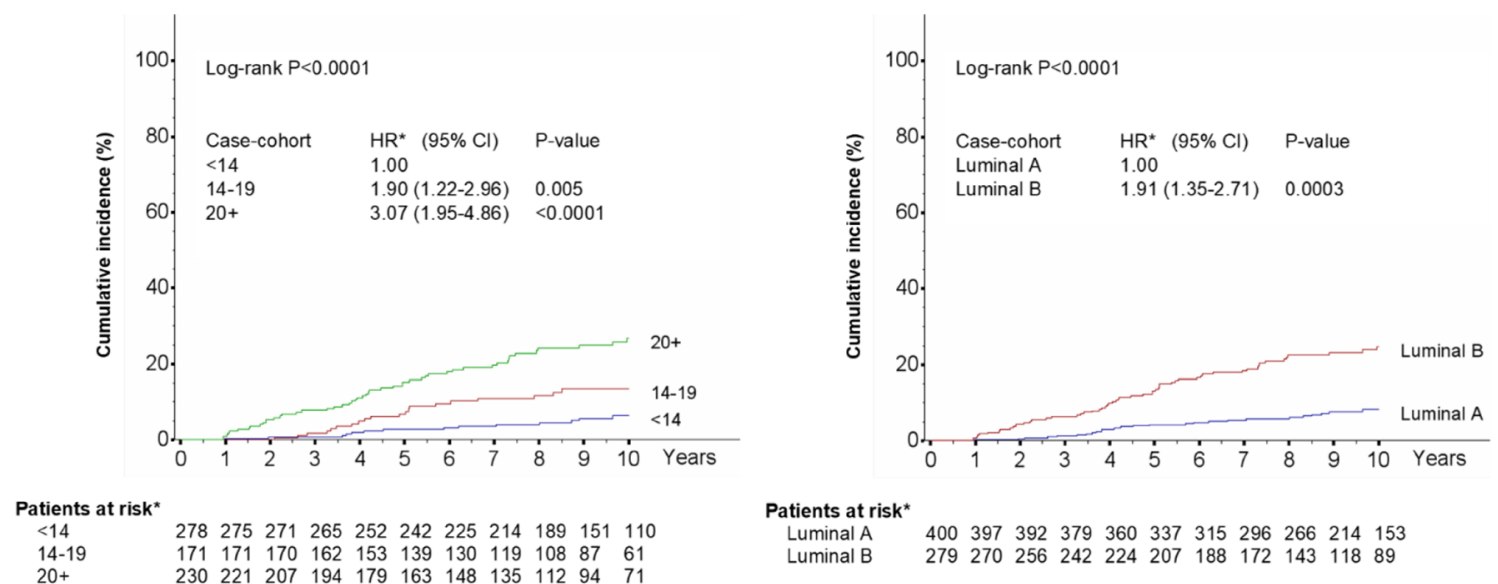

*Hazards ratios (HR) and 95\% confidence intervals ( $\mathrm{Cl}$ ) obtained from a multivariable Cox proportional Hazards regression model with inverse sub-cohort sampling probability weighting, adjusted for menopausal status, pT, pN, grade, PVI, ER, PgR and adjuvant therapy.

Fig. 1 Cumulative incidence of events in the subcohort $(N=679)$ and corresponding Hazards Ratios in the case-cohort $(N=982)$ according to Ki-67 (30-9) and derived intrinsic molecular subtype

Fig. 2 Event rate* in the subcohort and Hazard Ratio** for distant disease-free survival according to Ki-67 (HR set to 1.00 for $\mathrm{Ki}-67=14 \%$ ) in the case-cohort

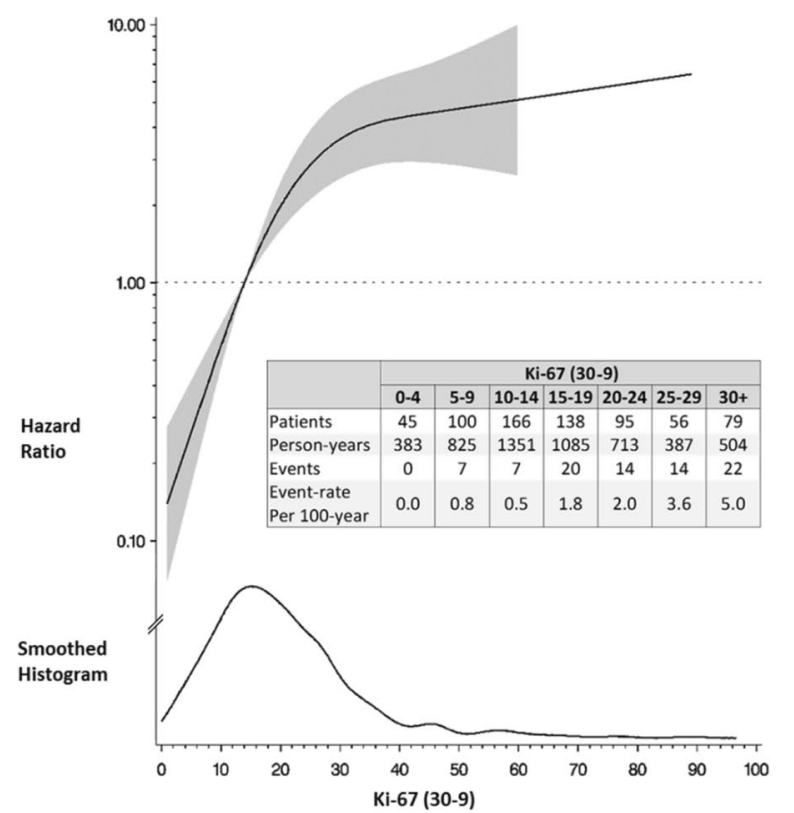

* calculated dividing the number of event by the number of patient-years at risk.

** using restricted cubic splines to proportional hazard regression model with inverse sub-cohort sampling probability weighting.
In the case-cohort, including additional cases reported outside of the subcohort and after adjusting for other prognostic factors (menopausal status, pT, pN, grade, PVI, ER, and $\mathrm{PgR}$ ) and for the type of adjuvant treatment received, Ki-67 remained significantly associated with DDFS. The relative risk of developing distant disease was 1.88 (95\% CI 1.20-2.93; $P=0.006$ ) for those with Ki-67 comprised between 14 and $19 \%$, and 3.06 (95\% CI 1.93-4.84; $P<0.0001$ ) for those with $\mathrm{Ki}-67 \geq 20 \%$ compared to those with $\mathrm{Ki}-67<14 \%$. Other independent prognostic factors include pT, pN, tumor grade, PVI. Patients receiving chemotherapy were also at higher risk of events (Table 2).

We used previously published criteria for the definition of surrogate BC molecular subtype using Ki-67 (Supplementary Table 1). In the subcohort, 400 (58.9\%) patients were classified as having "luminal A-like" and 279 (41.1\%) "luminal B-like" BC. The 5-year and 10-year cumulative incidence of distant metastasis (or BC-related death as first event) were respectively $4.2 \%$ (95\% CI 2.6-6.8) and $8.2 \%$ (95\% CI 5.7-11.9) in the Luminal A group and 13.2\% (95\% 
Table 3 Distribution of events and multivariable analysis

\begin{tabular}{|c|c|c|c|c|c|c|}
\hline & \multicolumn{3}{|c|}{ Sub-cohort $(n=679)$} & \multirow{2}{*}{$\begin{array}{l}\text { Additional } \\
\text { cases } \\
(n=303)\end{array}$} & \multicolumn{2}{|c|}{ Case-cohort $(n=982)$} \\
\hline & Patients & Events & $\begin{array}{l}\text { Event rate per } 100 \\
\text { patient-year }(95 \% \mathrm{CI})\end{array}$ & & $\operatorname{HR}(95 \% \mathrm{CI})^{\mathrm{a}}$ & $P$-value \\
\hline \multicolumn{7}{|c|}{ Molecular subtype } \\
\hline Luminal A-like & 400 & 27 & $0.83(0.56-1.20)$ & 88 & 1.00 & \\
\hline Luminal B-like & 279 & 57 & $2.84(2.17-3.65)$ & 215 & $1.91(1.35-2.71)$ & 0.0003 \\
\hline
\end{tabular}

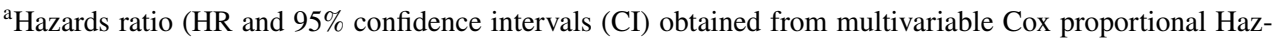
ards regression with inverse subcohort sampling probability weighting as defined in Miettinen (1976) using the SAS macro CCREGRESSION provided by Kulathinal et al. (2007), adjusted for menopausal status, pT, $\mathrm{pN}$, grade, PVI and adjuvant therapy
CI 9.6-17.9) and 24.5\% (95\% CI 19.4-30.8\%) in the Luminal B group (log-rank $P<0.0001$ ) (Fig. 1).

In the whole case-cohort, multivariable analysis confirmed statistically significant increased risk of events for women with "Luminal B-Like" BC compared to women with "Luminal A-Like" BC (HR $=1.91$; 95\% CI 1.35-2.71; $P=0.0003$ ), after adjustment for menopausal status, $\mathrm{pT}, \mathrm{pN}$, grade, PVI and adjuvant therapy (Table 3 ).

\section{Discussion}

Ki-67 labeling index is a clinically validated prognostic factor in early breast cancer. In the neoadjuvant setting, it predicts the likelihood of pathological complete response (pCR) to chemotherapy. Furthermore, Ki-67 in the residual tumor [12, 13], and changes of Ki-67 labeling index between primary and residual tumors are prognostic for long-term outcome $[14,15]$.

Decline of Ki-67 after few weeks of neoadjuvant endocrine therapy is correlated with a better long-term outcome of ER-positive HER2-negative disease [16] and Ki67 assessment in the residual tumor after neoadjuvant endocrine treatment is predictive of long-term outcome [17]. In the adjuvant setting, $\mathrm{Ki}-67$ is a prognostic marker for disease-free and overall survival independent of tumor stage $[18,19]$.

Despite its undisputed prognostic value, however, Ki-67 labeling index per se is not predictive of the benefit of adding chemotherapy to endocrine therapy in the treatment of patients with ER-positive HER2-negative early breast cancer [20]. To inform the choice of systemic treatment for these patients, Ki-67 labeling index should be used in combination with other parameters, including tumor grade and a quantitative evaluation of ER and progesterone receptor $(\mathrm{PgR})$ expression [3]. This has also been endorsed by the updated guidelines from the European Group of Tumor Markers [4].

By using a similar multifactorial approach, we have previously proposed a surrogate immunohistochemical definition of Luminal A-like and Luminal B-like breast cancer
[7] that could be helpful in tailoring the systemic treatment, especially when multiparameter molecular assays are not available.

Most of the aforementioned studies have been conducted using the MIB-1 monoclonal antibody to Ki-67. Here, we have shown that Ki-67 evaluation using the Ventana 30-9 rabbit monoclonal primary antibody, was similarly able to stratify patients with ER-positive HER2-negative breast cancer into prognostically distinct groups. Ki-67 evaluation in this cohort enabled maximizing the number of patients classified as having 'Luminal A-like' intrinsic subtype for whom the use of cytotoxic drugs could be at large avoided. Indeed, $400(58.9 \%)$ patients in the subcohort were classified as having "Luminal A-like" and 279 (41.1\%) "Luminal B-like" BC. These figures are strikingly similar to those obtained by Cheang and colleagues [21] using a rabbit monoclonal antibody to Ki-67 (clone SP6) in a series of 2847 hormone receptor-positive breast carcinomas, and showing a 59\% prevalence of Luminal A-like tumors. More recently, a study evaluating Ki-67 with the MIB-1 antibody in a series of 4718 patients with hormone receptor-positive disease also found a prevalence of Luminal A-like tumors of 58.2\% [22]. Currently, the scientific community is still concerned about a perceived lack of accuracy and reproducibility in the assessment of Ki-67 in the clinical setting. Major steps toward a harmonization of Ki-67 scoring in breast cancer, however, have been already made [9, 23-25], and it may be predicted that $\mathrm{Ki}-67$ assessment, with strict adherence to the international recommendations, will ultimately be included among the clinically useful biological parameters for the best treatment of patients with breast carcinoma.

Acknowledgements Ventana Medical Systems, Inc.

Open Access This article is distributed under the terms of the Creative Commons Attribution 4.0 International License (http://creativeco mmons.org/licenses/by/4.0/), which permits unrestricted use, distribution, and reproduction in any medium, provided you give appropriate credit to the original author(s) and the source, provide a link to the Creative Commons license, and indicate if changes were made. 


\section{References}

1. Scholzen T, Gerdes J (2000) The Ki-67 protein: from the known and the unknown. J Cell Physiol 182:311-322

2. Arima N, Nishimura R, Osako T, Okumura Y, Nakano M, Fujisue M, Nishiyama Y, Toyozumi Y (2019) Ki-67 index value and progesterone receptor status can predict prognosis and suitable treatment in node-negative breast cancer patients with estrogen receptorpositive and HER2-negative tumors. Oncol Lett 17:616-622

3. Goldhirsch A, Winer EP, Coates AS, Gelber RD, Piccart-Gebhart M, Thürlimann B, Senn HJ, Panel members (2013) Personalizing the treatment of women with early breast cancer: highlights of the St Gallen international expert consensus on the primary therapy of early breast cancer 2013. Ann Oncol 24:2206-2223

4. Duffy MJ, Harbeck N, Nap M, Molina R, Nicolini A, Senkus E, Cardoso F (2017) Clinical use of biomarkers in breast cancer: updated guidelines from the European group on tumor markers (EGTM). Eur J Cancer 75:284-298

5. Petrelli F, Viale G, Cabiddu M, Barni S (2015) Prognostic value of different cut-off levels of Ki-67 in breast cancer: a systematic review and meta-analysis of 64,196 patients. Breast Cancer Res Treat 153:477e91

6. Weidner N, Moore DH, Vartanian R (1994) Correlation of Ki-67 antigen expression with mitotic figure index and tumour grade in breast carcinomas using novel 'paraffin reactive MIB-1' antibody. Hum Pathol 25:337-342

7. Maisonneuve P, Disalvatore D, Rotmensz N, Curigliano G, Colleoni M, Dellapasqua S, Pruneri G, Mastropasqua MG, Luini A, Bassi F, Pagani G, Viale G, Goldhirsch A (2014) Proposed new clinicopathological surrogate definitions of luminal A and luminal B (HER2-negative) intrinsic breast cancer subtypes. Breast Cancer Res 16:R65

8. Prentice RL (1986) A case-cohort design for epidemiologic cohort studies and disease prevention trials. Biometrika 73:1-11

9. Dowsett M, Nielsen TO, A'Hern R, Bartlett J, Coombes RC, Cuzick J, Ellis M, Henry NL, Hugh JC, Lively T, McShane L, Paik S, Penault-Llorca F, Prudkin L, Regan M, Salter J, Sotiriou C, Smith IE, Viale G, Zujewski JA, Hayes DF, International Ki-67 in Breast Cancer Working Group (2011) Assessment of Ki67 in breast cancer: recommendations from the international Ki67 in breast cancer working group. J Natl Cancer Inst 103:1656-1664

10. Miettinen O (1976) Estimability and estimation in case-referent studies. Am J Epidemiol 103:226-235

11. Kulathinal S, Karvanen J, Saarela O, Kuulasmaa K (2007) Casecohort design in practice-experiences from the MORGAM project. Epidemiol Perspect Innov 4:15

12. Guarneri V, Piacentini F, Ficarra G, Frassoldati A, D’Amico R, Giovannelli S, Maiorana A, Jovic G, Conte P (2009) A prognostic model based on nodal status and $\mathrm{Ki}-67$ predicts the risk of recurrence and death in breast cancer patients with residual disease after preoperative chemotherapy. Ann Oncol 20:1193-1198

13. Montagna E, Bagnardi V, Viale G, Rotmensz N, Sporchia A, Cancello G, Balduzzi A, Galimberti V, Veronesi P, Luini A, Mastropasqua MG, Casadio C, Sangalli C, Goldhirsch A, Colleoni M (2015) Changes in PgR and Ki-67 in residual tumour and outcome of breast cancer patients treated with neoadjuvant chemotherapy. Ann Oncol 26:307-313

14. Tokuda E, Horimoto Y, Arakawa A, Himuro T, Senuma K, Nakai K, Saito M (2017) Differences in Ki67 expressions between preand post-neoadjuvant chemotherapy specimens might predict early recurrence of breast cancer. Hum Pathol 63:40-45

15. Chen R, Ye Y, Yang C, Peng Y, Zong B, Qu F, Tang Z, Wang Y, Su X, Li H, Yang G, Liu S (2018) Assessment of the predictive role of pretreatment $\mathrm{Ki}-67$ and $\mathrm{Ki}-67$ changes in breast cancer patients receiving neoadjuvant chemotherapy according to the molecular classification: a retrospective study of 1010 patients. Breast Cancer Res Treat 170:35-43

16. Dowsett M, Smith IE, Ebbs SR, Dixon JM, Skene A, A'Hern R, Salter J, Detre S, Hills M, Walsh G, IMPACT Trialists Group (2007) Prognostic value of Ki67 expression after short-term presurgical endocrine therapy for primary breast cancer. J Natl Cancer Inst 99:167-170

17. Ellis MJ, Tao Y, Luo J, A’Hern R, Evans DB, Bhatnagar AS, Chaudri Ross HA, von Kameke A, Miller WR, Smith I, Eiermann W, Dowsett M (2008) Outcome prediction for estrogen receptor-positive breast cancer based on postneoadjuvant endocrine therapy tumor characteristics. J Natl Cancer Inst 100:1380-1388

18. de Azambuja E, Cardoso F, de Castro G, Jr Colozza M, Mano MS, Durbecq V, Sotiriou C, Larsimont D, Piccart-Gebhart MJ, Paesmans M (2007) Ki-67 as prognostic marker in early breast cancer: a metaanalysis of published studies involving 12,155 patients. Br J Cancer 96:1504-1513

19. Abubakar M, Orr N, Daley F, Coulson P, Ali HR, Blows F, Benitez J, Milne R, Brenner H, Stegmaier C, Mannermaa A, Chang-Claude J, Rudolph A, Sinn P, Couch FJ, Devilee P, Tollenaar RA, Seynaeve C, Figueroa J, Sherman ME, Lissowska J, Hewitt S, Eccles D, Hooning MJ, Hollestelle A, Martens JW, van Deurzen CH, Investigators K, Bolla MK, Wang Q, Jones M, Schoemaker M, Wesseling J, van Leeuwen FE, Van 't Veer L, Easton D, Swerdlow AJ, Dowsett M, Pharoah PD, Schmidt MK, Garcia-Closas M (2016) Prognostic value of automated KI67 scoring in breast cancer: a centralised evaluation of 8088 patients from 10 study groups. Breast Cancer Res 18:104

20. Viale G, Regan MM, Mastropasqua MG, Maffini F, Maiorano E, Colleoni M, Price KN, Golouh R, Perin T, Brown RW, Kovács A, Pillay K, Ohlschlegel C, Gusterson BA, Castiglione-Gertsch M, Gelber RD, Goldhirsch A, Coates AS, International Breast Cancer Study Group (2008) Predictive value of tumor Ki-67 expression in two randomized trials of adjuvant chemoendocrine therapy for node-negative breast cancer. J Natl Cancer Inst 100:207-212

21. Cheang MCU, Chia SK, Voduc D, Gao D, Leung S, Snider J, Watson M, Davies S, Bernard PS, Parker JS, Perou CM, Ellis MJ, Nielsen TO (2009) Ki67 index, HER2 status, and prognosis of patients with luminal B breast cancer. J Natl Cancer Inst 101:736-750

22. Viale G, de Snoo FA, Slaets L, Bogaerts J, Van 't Veer L, Rutgers EJ, Piccart-Gebhart MJ, Stork-Sloots L, Glas A, Russo L, Dell'Orto P, Tryfonidis K, Litière S, Cardoso F, MINDACT investigators (2018) Immunohistochemical versus molecular (BluePrint and MammaPrint) subtyping of breast carcinoma. Outcome results from the EORTC 10041/BIG 3-04 MINDACT trial. Breast Cancer Res Treat 167:123-131

23. Polley MY, Leung SC, McShane LM, Gao D, Hugh JC, Mastropasqua MG, Viale G, Zabaglo LA, Penault-Llorca F, Bartlett JM, Gown AM, Symmans WF, Piper T, Mehl E, Enos RA, Hayes DF, Dowsett M, Nielsen TO, International Ki67 in Breast Cancer Working Group of the Breast International Group and North American Breast Cancer Group (2013) An international Ki67 reproducibility study. J Natl Cancer Inst 105:1897-1906

24. Polley MY, Leung SC, Gao D, Mastropasqua MG, Zabaglo LA, Bartlett JM, McShane LM, Enos RA, Badve SS, Bane AL, Borgquist S, Fineberg S, Lin MG, Gown AM, Grabau D, Gutierrez C, Hugh JC, Moriya T, Ohi Y, Osborne CK, Penault-Llorca FM, Piper T, Porter PL, Sakatani T, Salgado R, Starczynski J, Lænkholm AV, Viale G, Dowsett M, Hayes DF, Nielsen TO (2015) An international study to increase concordance in Ki67 scoring. Mod Pathol 28:778-786 
25. Leung SCY, Nielsen TO, Zabaglo L, Arun I, Badve SS, Bane AL, Bartlett JMS, Borgquist S, Chang MC, Dodson A, Enos RA, Fineberg S, Focke CM, Gao D, Gown AM, Grabau D, Gutierrez C, Hugh JC, Kos Z, Lænkholm AV, Lin MG, Mastropasqua MG, Moriya T, Nofech-Mozes S, Osborne CK, Penault-Llorca FM, Piper T, Sakatani T, Salgado R, Starczynski J, Viale G, Hayes DF, McShane LM, Dowsett M (2016) Analytical validation of a standardized scoring protocol for Ki67: phase 3 of an international multicenter collaboration. NPJ Breast Cancer 2:16014
Publisher's Note Springer Nature remains neutral with regard to jurisdictional claims in published maps and institutional affiliations. 